\title{
The Effect of E-Learning on the Attitude Toward Dengue Prevention and the Acceptance of Dengue Vaccination
}

This article was published in the following Dove Press journal: Patient Preference and Adherence

\author{
Mohammad Ali' \\ Amirah Adlia ${ }^{2}$ \\ Auliya A Suwantika $\mathbb{1 D}^{3-5}$ \\ 'Department of Curriculum and \\ Educational Technology, Faculty of \\ Educational Sciences, Universitas \\ Pendidikan Indonesia, Bandung, 40I54, \\ Indonesia; ${ }^{2}$ Department of Pharmaceutics, \\ School of Pharmacy, Bandung Institute of \\ Technology, Bandung, 40I32, Indonesia; \\ ${ }^{3}$ Department of Pharmacology and Clinical \\ Pharmacy, Faculty of Pharmacy, Universitas \\ Padjajaran, Bandung, 40I32, Indonesia; \\ ${ }^{4}$ Center of Excellence in Higher Education \\ for Pharmaceutical Care Innovation, \\ Universitas Padjadjaran, Bandung, 40I32, \\ Indonesia; ${ }^{5}$ Center for Health Technology \\ Assessment, Universitas Padjadjaran, \\ Bandung, 40I32, Indonesia
}

Correspondence: Auliya A Suwantika Faculty of Pharmacy, Universitas Padjadjaran, Jl. Raya Bandung-Sumedang Km. 2I, Jatinangor, Sumedang, 45363, Indonesia

Email auliya@unpad.ac.id
Background: A community's attitude toward dengue prevention and its acceptance of dengue vaccine and vaccination play an essential role in the success of the dengue infection prevention program. To develop their attitude and acceptance, the implementation of learning media is required.

Objective: The objective of the study was to examine the effectiveness of e-learning for developing the community's attitude toward dengue prevention and its acceptance of dengue vaccine and vaccination.

Methods: This study employed a quasi-experimental method with pre- and post-test design by involving 85 subjects that were purposively selected from the low-prevalence area of dengue infection in the City of Bandung, West Java Province, Indonesia. A valid and reliable questionnaire was delivered during pre- (day 1) and post-test (day 7). For the e-learning, it was given on day 1 after completing the pre-test. A descriptive statistical method was applied to describe the research variables, to analyze the correlation between the subjects' attitude and acceptance, and to examine the significant differences (pre- and post-test) between the subjects' attitude toward dengue prevention and their acceptance of dengue vaccine and vaccination.

Results: Approximately $88.24 \%$ and $11.76 \%$ of subjects have good and fair knowledge about dengue disease, respectively. Concerning knowledge about dengue vaccine, $44.71 \%$ and $55.29 \%$ of them them have good and fair knowledge, respectively. In particular, there is an increase in their attitude toward dengue prevention ( $p$-value $<0.05$ ), their acceptance of dengue vaccine $(p$-value $<0.05)$ and their acceptance of dengue vaccination program $(p$-value $<0.05$ ) after they got information from e-learning.

Conclusion: E-learning could have significant effects to increase the community's attitude toward dengue prevention and their acceptance of dengue vaccine and vaccination.

Keywords: quasi-experimental, pre-test, post-test, questionnaire, correlation analysis

\section{Introduction}

Dengue infection is a type of infectious disease that has become one of the serious public health issues in tropical countries. The manifestation of dengue infection ranges from dengue fever (DF) to the more severe forms, dengue hemorrhagic fever (DHF) and dengue shock syndrome (DSS). ${ }^{1}$ Indonesia is one of the vulnerable tropical countries that may suffer endemic dengue disease. According to data from the Ministry of Health $(\mathrm{MoH})$, there are 23 among 100,000 in the Indonesian population suffering from dengue disease and an annual fatality rate is reported to be $0.75 \% .^{2}$ In 2015 , there were approximately 129,650 dengue cases in 34 
provinces in Indonesia, and 1071 of them were fatal cases. $^{2}$ Another data set in 2017 reported 201,885 dengue cases and 1585 deaths. $^{3}$ This increasing number was caused by climate change and low community awareness about the importance of keeping their environment clean. ${ }^{2}$

In the most populous province in Indonesia, West Java Province, the number of dengue infections was reported to be 36,631 cases ( 77.31 cases per 100,000 population) and the fatality rate was estimated to be $0.74 \%{ }^{4}$ The number of dengue cases is consistently increasing, indicating the need of comprehensive disease prevention strategies. To deal with this problem, the government has spent a budget of approximately USD 381 million on dengue prevention, which was reported to be the highest amount among Southeast Asian countries. ${ }^{1}$ Nevertheless, the attempt to prevent dengue infection is constrained due to its borderless spread. In a comparison with other prevention strategies, dengue vaccination is considered to be the most costeffective intervention to decrease the number of dengue infections since the human immune response plays an essential role in pathogenic infectious disease. ${ }^{5}$ In 2016, the Indonesian Food and Drug Authority issued an official license for the use of dengue vaccine in Indonesia. ${ }^{6}$ Due to limited data on its economic aspect and the community's acceptance of this particular vaccine, this vaccine has not been included in the national immunization program. ${ }^{7}$ The implementation of dengue vaccination in Indonesia needs support from the community. Effective learning media are required to enhance the community's attitude toward dengue prevention and the acceptance of dengue vaccination program.

E-learning is one of the effective learning tools for developing the learners' attitude and other behavioral traits. ${ }^{8}$ It is a medium of creating, managing and distributing information by utilizing information and communication technology (ICT). ${ }^{9}$ In recent decades, the use of ICT for educational purposes has increased, and the spread of network technologies has caused e-learning practices to evolve significantly. ${ }^{10}$ The development of e-learning may use any kind of learning management system (LMS). Through this system, e-learning can result in a network-enabled transfer of attitude to a large number of recipients at the same or different times. ${ }^{11,12}$

This study was targeted to address problems dealing with the extensive use of e-learning for developing the community's attitude and acceptance of dengue prevention strategies to be conducted in the City of Bandung, West Java Province, Indonesia. This study specifically aimed to examine the effectiveness of e-learning for developing the community's attitude toward dengue prevention and its acceptance of dengue vaccine and vaccination. Hopefully, this study can give a contribution to stakeholders by providing an appropriate mode of adult learning media.

\section{Methods}

\section{E-Learning}

In this study, we developed e-learning by using the modular object-oriented dynamic learning environment (Moodle), which was targeted to give positive impact on the community's attitude and acceptance. The Moodle was selected since it has been acknowledged as a good platform in distance learning and telework activity. ${ }^{13}$ As an LMS application, it also can be used to extend learning environments by using community-sourced plugins. In addition, blended and distance learning in school, workplace or other sectors can also use this tool.

\section{Questionnaire}

This study employed a quasi-experimental method by using a one-shot case study with pre- and post-test design. It involved 85 subjects, of whom 35 males $(41.18 \%)$ and 50 females $(58.82 \%)$, that were selected from the lowestprevalence area in the City of Bandung, West Java Province, Indonesia. A valid and reliable questionnaire using a Likert scale was applied to measure the subjects' attitude toward dengue prevention and their acceptance of dengue vaccine and vaccination (see Table 1). The validity and reliability of the questionnaire was reviewed by two experts and assessed by using the Cronbach Alpha technique, respectively. The questionnaire was delivered in pre(day 1) and post-test (day 7). For the e-learning, it was given on day 1 after completing the pre-test. A descriptive statistical method was applied to describe the research variables, to analyze the correlation between the subjects' attitude and acceptance, and to examine the significant differences (pre- and post-test) between the subjects' attitude toward dengue prevention and their acceptance of dengue vaccine and vaccination. The process of data analysis utilized SPSS.

Ethical approval for the study was obtained from the Ethics Committee of Universitas Padjadjaran, Indonesia (registration number: 89/UN6.KEP/EC/2019), and this study was conducted in accordance with the Declaration of Helsinki. Survey participants signed an informed 
Table I Statements on Attitude Toward Dengue Prevention and Acceptance of Dengue Vaccination

\begin{tabular}{|c|c|c|c|c|c|c|}
\hline \multicolumn{2}{|c|}{ Statements } & $\begin{array}{l}\text { Strongly } \\
\text { Disagree }\end{array}$ & Disagree & $\begin{array}{c}\text { No } \\
\text { Opinion }\end{array}$ & Agree & $\begin{array}{c}\text { Strongly } \\
\text { Agree }\end{array}$ \\
\hline \multicolumn{7}{|c|}{ Attitude toward dengue prevention } \\
\hline $\begin{array}{l}1 \\
2 \\
3 \\
4 \\
5 \\
6 \\
7 \\
8 \\
9\end{array}$ & $\begin{array}{l}\text { Dengue infection is severe and can cause death } \\
\text { Virus that can be transmitted by Aedes aegypti mosquito is the major cause of } \\
\text { dengue infection } \\
\text { Nausea, vomiting and fever are major symptoms of dengue infection } \\
\text { Dengue infection can be diagnosed through laboratory test } \\
\text { Neighborhoods with standing water and high humidity are dengue high-risk } \\
\text { places } \\
\text { Patients with dengue infection need hospitalization } \\
\text { Treatment of dengue infection is high-cost } \\
\text { Societal participation is a key factor on dengue prevention } \\
\text { Doing } 3 M \text {, which stands covering (Menutup) and cleaning (Menguras) water } \\
\text { containers, and burying (Mengubur) discarded water containers, can prevent } \\
\text { dengue infection } \\
\text { The government of Indonesia has been reducing the prevalence of dengue } \\
\text { infection successfully }\end{array}$ & & & & & \\
\hline \multicolumn{7}{|c|}{ Acceptance of dengue vaccination } \\
\hline $\begin{array}{l}1 \\
2 \\
3 \\
4 \\
5 \\
6\end{array}$ & $\begin{array}{l}\text { Dengue vaccination can increase the immunity } \\
\text { Dengue vaccination has no serious adverse events } \\
\text { Dengue vaccine is already available in Indonesia } \\
\text { Dengue vaccine can be administered in children and adults } \\
\text { Dengue vaccine is required to prevent dengue infection } \\
\text { Dengue vaccine should be available in all healthcare facilities (eg, clinics, } \\
\text { primary healthcare centers and hospitals) } \\
\text { Product information about dengue vaccine should be delivered prior to } \\
\text { vaccination } \\
\text { Dengue vaccination should be nationwide program and free of charge } \\
\text { Dengue vaccine is required to be implemented in my neighborhood } \\
\text { The price of dengue vaccine in the private market (IDR } 1.3 \text { million) is } \\
\text { proportional to its benefits }\end{array}$ & & & & & \\
\hline
\end{tabular}

consent form prior to enrollment even though the study met the criteria for exemption. The incentive for each respondent completing the survey (pre- and post-test) was a phone credit of IDR 20,000 (US\$ 1.38).

\section{Results}

The e-learning module for developing the community's attitude of dengue prevention is accessible at http://www. elearningdbd.moodlecloud.com. Its feature can be seen in Figure 1A. The e-learning offers a course on attitude of dengue prevention in the form of a modular instruction and video, in which every learner can choose what to learn, chat with the instructor and respond to quizzes, as presented in Figure 1B. In addition, Figure 1C represents an example of the course content that a learner can access.
Table 2 summarizes demographic characteristic of respondents. The majority of respondents were females $(80 \%)$, in the age group of $18-24$ years old $(73 \%)$, had college education background or higher $(63 \%)$ and had income of more than IDR 1 million per month (44\%).

Based on expert judgment, the questionnaire's content was considered to be valid. It was also considered to be reliable because of its reliability index $(a=0.86)$. The results of this study showed that among 85 subjects involved in this study, $88.24 \%$ and $11.76 \%$ of them have good and fair knowledge about dengue disease, respectively. Concerning knowledge about dengue vaccine, $44.71 \%$ and $55.29 \%$ of them have good and fair knowledge, respectively. Concerning the attitude and acceptance, a questionnaire using a Likert scale (5 scales) was applied. 
$\mathbf{A} \leftarrow \rightarrow \mathrm{C} \oplus$ elearningdbd.moodlecloud.com/?redirect $=0$

\section{E $\quad$ E-Learning DBD $\quad$ ENGLISH (EN) .}

\begin{tabular}{l} 
Home \\
Cashboard \\
Calendar \\
\hline Private files \\
\hline Site administration \\
\hline
\end{tabular}

Knowledge about Dengue Prevention

The implementation of dengue vaccination in Indonesia needs supports from the community. An effective learning media is required to enhance the community's attitude toward dengue prevention and the acceptance to dengue vaccination program.

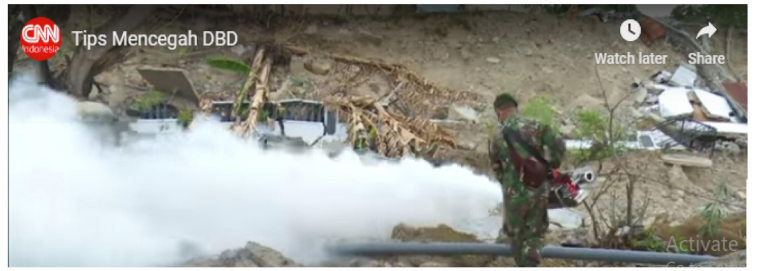

$\mathbf{B} \leftarrow \rightarrow c$ 命 (1) 2 W https://elearningdbd.moodlecloud.com $\cdots$ 的 Q Search

III $₫$

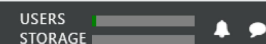

\section{$\equiv \quad$ E-Learning DBD $\quad$ ENGLISH (EN)}

$\Delta$

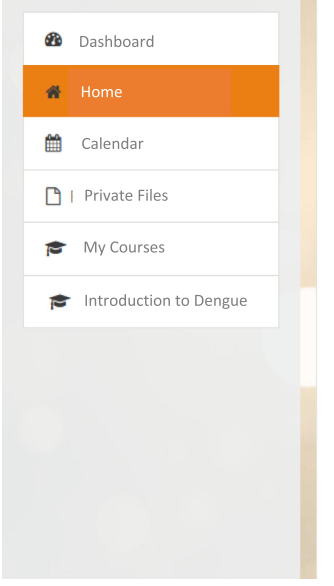

\section{Course Category}

Beginner (1)

Intermediate ${ }_{(1)}$

Advanced ${ }_{(1)}$

\section{Available Courses}

Introduction to Dengue Disease

Symptoms and Causes of Dengue Disease

Treatment of Dengue Disease

C

(1) A https://elearningdbd.moodlecloud.com/course/view.php?id=3

… 四| Q Search

IIII

\section{$\equiv \quad$ E-Learning DBD}

ENGLISH (EN)

$\Delta$

\begin{tabular}{|l|l|}
\hline Introduction to Dengue \\
\hline D & Participants \\
$\square$ & Badges \\
\hline (1) & Grades \\
$\square$ & Definition \\
$\square$ & Topic 2 \\
$\square$ & Topic 3 \\
$\square$ & Topic 4 \\
\hline
\end{tabular}

Dashboard

* Home

Calendar
Introduction to Dengue Disease

\section{Background}

Dengue infection is a type of infectious disease that becomes one of serious public health issues in tropical countries. The manifestation of dengue infection ranges from dengue fever (DF) to the more severe form, dengue haemorrhagic fever (DHF) and dengue shock syndrome (DSS). Indonesia is one of the vulnerable tropical countries that may suffer endemic dengue disease. According to data from the Ministry of Health, there are 23 among 100,000 Indonesian population suffered from dengue disease In 2015, there were approximately 129,650 do cases. Another data in 2017 reported 201,885 dengue cases and 1,585 deaths. This increasing number was caused by climate change and low community awareness about the importance of keeping their environment clean.

As the most populous province in Indonesia, the number of dengue infections in West Java Province was reported to be 36,631 cases (77.31 cases per 100,000 population). The number of dengue case that is consistently increasing indicates the need of comprehensive disease prevention strategies. To deal with this problem, the government has spent budget approximately USD 381 million for dengue prevention, which was reported to be the highest budget among Southeast Asian countries. Nevertheless, there is a constraint in the attempt of preventing dengue infection due to its borderless spread. In a comparison with other prevention strategies, dengue vaccination is considered to be the most cost-effective intervention to decrease the number of dengue infection since the human immune response plays an essential role in pathogenic infectious disease.

Figure I (A) The feature. (B) Course categories. (C) A course example. 
Table 2 Demographic Characteristics of Respondents

\begin{tabular}{|c|c|c|c|}
\hline \multicolumn{2}{|c|}{ Demographic Characteristics } & \multirow{3}{*}{$\begin{array}{c}\text { Number } \\
35 \\
50\end{array}$} & \multirow{3}{*}{$\begin{array}{c}\% \\
41.18 \% \\
58.82 \%\end{array}$} \\
\hline Sex & Male & & \\
\hline & Female & & \\
\hline \multirow[t]{6}{*}{ Age } & $18-24$ & 62 & $72.94 \%$ \\
\hline & $25-34$ & 12 & $14.12 \%$ \\
\hline & $35-44$ & 4 & $4.71 \%$ \\
\hline & $45-54$ & 4 & $4.71 \%$ \\
\hline & $55-64$ & 3 & $3.53 \%$ \\
\hline & $>64$ & 0 & $0 \%$ \\
\hline \multirow[t]{4}{*}{ Education level } & Elementary school & I & $1.18 \%$ \\
\hline & Junior high school & 0 & $0 \%$ \\
\hline & Senior high school & 30 & $35.29 \%$ \\
\hline & College or higher & 54 & $63.53 \%$ \\
\hline \multirow[t]{4}{*}{ Employment status } & Employee & 30 & $35.29 \%$ \\
\hline & Unemployment & 9 & $10.59 \%$ \\
\hline & Retired & $\mathrm{I}$ & $1.18 \%$ \\
\hline & Others & 45 & $52.94 \%$ \\
\hline \multirow[t]{5}{*}{ Income per month } & $<$ IDR I million & 37 & $43.53 \%$ \\
\hline & IDR I-3 million & 22 & $25.88 \%$ \\
\hline & IDR 3-6 million & 16 & $18.82 \%$ \\
\hline & IDR 6-10 million & 8 & $9.41 \%$ \\
\hline & >IDR 10 million & 2 & $2.35 \%$ \\
\hline
\end{tabular}

To represent descriptive statistics, the scales were categorized into three criteria: unfavorable or not good (1 and 2), fairly favorable or fairly good (3) and favorable or good (4 and 5). The descriptive statistics (pre- and post-test) of the subjects' attitude toward dengue prevention, the subjects' acceptance of dengue vaccine and the subjects' acceptance of dengue vaccination are presented in Tables 3, Tables 4-5, respectively.

Wilcoxon signed rank and McNemar tests were applied to analyze the effect of e-learning on the subjects' attitude toward dengue prevention and the effect of e-learning on their acceptance of dengue vaccine and dengue vaccination, respectively. Both tests were done by comparing pre- and post-test by considering $\mathrm{a}=0.05$. The results are presented in Tables 6 and 7 .

Table 3 Subjects' Attitude Based on Pre- and Post-Test

\begin{tabular}{|l|c|c|c|}
\hline Criteria & $\begin{array}{c}\% \text { of } \\
\text { Pre-Test }\end{array}$ & $\begin{array}{c}\% \text { of } \\
\text { Post-Test }\end{array}$ & $\begin{array}{c}\text { Asymp. Sig } \\
\text { (2 Tailed) }\end{array}$ \\
\hline Favorable & $81.18 \%$ & $97.65 \%$ & \\
Fairly Favorable & $18.82 \%$ & $2.35 \%$ & 000 \\
Unfavorable & $0 \%$ & $0 \%$ & \\
\hline
\end{tabular}

Table 4 Subjects' Acceptance of Dengue Vaccine Based on Preand Post-Test

\begin{tabular}{|l|c|c|c|}
\hline Criteria & $\begin{array}{c}\% \text { of } \\
\text { Pre-Test }\end{array}$ & $\begin{array}{c}\% \text { of } \\
\text { Post-Test }\end{array}$ & $\begin{array}{c}\text { Asymp. Sig } \\
\text { (2 Tailed) }\end{array}$ \\
\hline Yes & $16.47 \%$ & $38.82 \%$ & \\
No & $83.53 \%$ & $61.18 \%$ & 000 \\
\hline
\end{tabular}

Table 5 Subjects' Acceptance of Dengue Vaccination Based on Pre- and Post-Test

\begin{tabular}{|l|c|c|c|}
\hline Criteria & $\begin{array}{c}\% \text { of } \\
\text { Pre-Test }\end{array}$ & $\begin{array}{c}\% \text { of } \\
\text { Post-Test }\end{array}$ & $\begin{array}{c}\text { Asymp. Sig } \\
\text { (2 Tailed) }\end{array}$ \\
\hline Yes & $44.71 \%$ & $82.35 \%$ & \\
No & $55.29 \%$ & $17.65 \%$ & 000 \\
\hline
\end{tabular}

Table 6 The Effect of e-Learning on Attitude Toward Dengue Prevention

\begin{tabular}{|l|c|c|c|}
\hline Pre-Test and Post-Test Results $(n=85)$ \\
\hline $\begin{array}{l}\text { Negative } \\
\text { Ranks }\end{array}$ & $\begin{array}{c}\text { Positive } \\
\text { Ranks }\end{array}$ & Ties & $\begin{array}{c}\text { Asymp. Sig. (2- } \\
\text { Tailed) }\end{array}$ \\
\hline $8^{\mathrm{a}}$ & $27^{\mathrm{b}}$ & $50^{\mathrm{c}}$ & 0.000 \\
\hline
\end{tabular}

Notes: ${ }^{\text {a }}$ Post-test $<$ pre-test; ${ }^{\mathrm{b}}$ post-test $>$ pre-test; ${ }^{\mathrm{c}}$ post-test $=$ pre-test.

\section{Discussion}

The government of Indonesia has attempted several strategies, such as vector control and environment management by involving communities, to prevent dengue infection and to decrease the rate of virus infection in the population. Nevertheless, the number of dengue cases tends to increase annually. It might be caused by poor participation of the local community in the prevention strategies. In addition, the heterogeneity of their education and attitude is responsible for the program achieved an optimum result. ${ }^{2}$ On the other hand, dengue vaccination is potentially considered to decrease the number of dengue infections and to save treatment cost. ${ }^{14-16}$ Vaccination has been known as the most effective strategy to prevent infectious diseases, including dengue infection, in Indonesia. ${ }^{17-21}$ Theoretically, the dengue vaccination program in Indonesia is able to control the spread of dengue disease, as $\mathrm{MoH}$ aimed to achieve a vaccination coverage of at least $69 \% .^{2}$ However, this program needs support from the community. A study in some developing countries indicated that a community's acceptance of dengue vaccine and vaccination was associated with the successful implementation of a vaccination program. ${ }^{7}$ Learning from 
Table 7 The Effect of e-Learning on Acceptance of Dengue Vaccine and Vaccination

\begin{tabular}{|l|c|c|c|c|c|c|c|c|}
\hline \multicolumn{2}{|l|}{ Pre-Test } & \multicolumn{2}{|c|}{ Post-Test } & & & \multicolumn{2}{c|}{ Post-Test } & Exact Sig. (2-Tailed) (n=85) \\
\hline Yes & No & Yes & No & Pre-test & & Yes & No & 0.000 \\
14 & 71 & 33 & 52 & & Yes & 12 & 2 & \\
$16.47 \%$ & $83.53 \%$ & $38.82 \%$ & $61.18 \%$ & & No & 21 & 50 & \\
\hline
\end{tabular}

the implementation of other vaccination programs in Indonesia, the community's attitude toward dengue prevention and its acceptance of dengue vaccination are considered as key factors in the success of dengue prevention efforts in Indonesia. ${ }^{22}$

Pre-test results of the subjects' attitude toward dengue prevention indicate that $81.18 \%, 18.82 \%$ and $0 \%$ of them have favorable, fairly favorable and unfavorable attitudes, respectively. Post-test results of subjects' attitude toward dengue prevention indicate that $97.65 \%, 2.35 \%$ and $0 \%$ of them have favorable, fairly favorable attitude and unfavorable attitude, respectively. The increase in their favorable attitude (16.47\%) and the decrease in their fairly favorable attitude $(16.47 \%)$ are significant, as indicated by asymptotic significance (2-tailed) of $p$-value $<0.05$. Furthermore, pre-test results of the subjects' acceptance of dengue vaccine indicate $16.47 \%$ and $83.53 \%$ of them accept and reject it, respectively. Post-test results indicate $38.82 \%$ and $61.15 \%$ of them accept and reject it, respectively. There is an increase in their acceptance of dengue vaccine after they got information from e-learning. The increase in their acceptance $(22.35 \%)$ and the decrease in their rejection $(22.45 \%)$ are significant, as indicated by asymptotic significance (2-tailed) of $p$-value $<0.05$. In particular, pretest results of the subjects' acceptance of dengue vaccination program indicate $44.71 \%$ and $55.29 \%$ of them accept and reject it, respectively. Post-test results indicate $82.35 \%$ and $17.65 \%$ of them accept and reject it, respectively. There is an increase in their acceptance after they got information from e-learning. The increase in their acceptance $(37.61 \%)$ and the decrease in their rejection $(37.64 \%)$ are significant, as indicated by asymptotic significance (2-tailed) of $p$-value $<0.05$.

In this study, we ordered the subjects based on their age, educational background and occupation in order to analyze the correlation (pre- and post-test) with their attitude toward dengue prevention, acceptance of dengue vaccine and dengue vaccination. Using Spearman rank, correlation analysis results indicate there is no significant correlation between age and attitude toward dengue prevention (pre-test with $r$-value $=0.063, p$-value $=5.67$; and post-test with $r$-value $=-0.191, p$-value $=0.080)$, age and acceptance of dengue vaccine (pre-test with $r$-value $=$ $-0.125, p$-value $=0.256$; and post-test with $r$-value $=0.113$, $p$-value $=0.303$ ), age and acceptance of dengue vaccination (pre-test with $r$-value $=0.074, p$-value $=0.503$; and post-test with $r$-value $=-0.005, p$-value $=0.965)$. The results also indicate there is a significant correlation between education background and attitude toward dengue prevention based on pre-test $(r$-value $=0.362, p$-value $=0.001)$, but the correlation based on post-test is not significant ( $r$ value $=0.130, p$-value $=0.234$ ). Additionally, there is no significant correlation between education background and acceptance of dengue vaccine (pre-test with $r$-value $=$ $-0.209, \quad p$-value $=0.555$; and post-test with $r$-value $=$ $-0.001, p$-value $=0.234)$, education background and acceptance of dengue vaccination (pre-test with $r$-value $=0.169$, $p$-value $=0.123$; and post-test with $r$-value $=0.048$, $p$-value $=0.666)$. Furthermore, the results also indicate there is no significant correlation between level of occupation and attitude toward dengue prevention (pre-test with $r$-value $=0.036, p$-value $=0.746$; and post-test with $r$-value $=$ $-0.035, p$-value $=0.747$ ), level of occupation and acceptance of dengue vaccine (pre-test with $r$-value $=0.169$, $p$-value $=0.123$; and post-test with $r$-value $=0.048$, $p$-value $=0.666$ ), level of occupation and acceptance of dengue vaccination (pre-test with $r$-value $=0.106$, $p$-value $=0.333$; and post-test with $r$-value $=-0.019$, $p$-value $=0.861)$. Based on the correlation analysis, the only significant correlation is between education background and attitude toward dengue prevention on pretest. It can be interpreted that the higher subjects' education background, the more favorable attitude in a setting before they got information from the e-learning, but their attitude was not significantly correlated with the level of education, thereafter.

Furthermore, the results of Wilcoxon signed rank test indicate negative and positive ranks. There are 8 subjects with negative rank (the result of post- is lower than pretest), 27 subjects with positive rank (the result of post- is higher than pre-test result), and 50 subjects neither negative nor positive (the result of pre- and post-test is equal) 
with asymptotic significance (2-tailed) of $p$-value $<0.05$. There is a significant difference between the results in preand post-test. Additionally, the result in post-test is higher than pre-test. It can be interpreted that e-learning has a significant effect on the subjects' attitude toward dengue prevention. Taking McNemar test into account, the results indicate that the subjects' acceptance of dengue vaccine and vaccination increases from $16.47 \%$ to $38.82 \%$ after e-learning application. In contrast, the percentage of those who responded no (reject) also decreases from $83.53 \%$ to $61.18 \%$. Comparing pre- and post-test data, the results indicate a significant difference, as represented by exact significance (2-tailed) with $p$-value $<0.05$. This result leads to a conclusion that e-learning has significant effect on the subjects' attitude toward dengue prevention, their acceptance of dengue vaccine and vaccination.

Despite the fact that the study has a major limitation in the sample size, it has significant implication on the effectiveness of e-learning application as one of efforts to prevent dengue infection. To our knowledge, this e-learning program for dengue prevention by using the Moodle platform is the first to be implemented in Indonesia. Following the results of this study, we encourage stakeholders to enhance the use of e-learning, for instance with the Moodle platform, to improve the community's attitude toward dengue prevention and the community's acceptance of dengue vaccine and vaccination. To make an effective utilization of e-learning, there are several factors to be considered, such as learner, learning materials, learning atmosphere and technology. ${ }^{23}$ For the application in formal and non-formal education, e-learning can be applied as a supplement, a complement or a substitute. ${ }^{24}$ As a supplement, the learners undertake regular teachinglearning processes, and they are free to decide whether or not to take the e-learning program for enrichment. As a complement, the learners undertake regular teachinglearning processes, and the teacher assigns them to take an e-learning program as a reinforcement. As a substitute, the teacher undertakes the teaching-learning process through the internet, which means the function of e-learning is as a substitute for the regular teaching-learning process. To accelerate the implementation of e-learning, Clark et al highlighted three valuable instructional methods, such as practice with tailored feedback, integration of collaboration with self-study and use of simulation. ${ }^{25}$ In the context of sustainability factors for e-learning initiatives in the health sector, these approaches can be implemented by the government of Indonesia to enhance interactivity, increase flexibility, reach more learners and keep the content updated.

\section{Conclusions}

The subjects involved in this study vary concerning their gender, age, education background and employment status. The community's attitude toward dengue prevention is favorable, and it increases after they are involved in e-learning. They also indicate their acceptance of dengue vaccine and vaccination, and somehow, after they are being involved in e-learning, the proportion of those who previously accept the dengue vaccine and vaccination increases, and the proportion of those who previously reject the dengue vaccine and vaccination decreases. A further study is required to compare the effectiveness of e-learning with other education platforms.

\section{Author Contributions}

Conceptualization: MA and AAS; methodology: MA and AAS; software: AA and AAS; validation: AA and AAS; formal analysis: AA and AAS; investigation: $M A$ and AAS; resources: MA and AA; writing, original draft preparation: MA and AAS; writing, review and editing: AA and AAS; supervision: AAS; project administration: AA; All authors made substantial contributions to conception and design, acquisition of data, or analysis and interpretation of data; took part in drafting the article or revising it critically for important intellectual content; agreed to submit to the current journal; gave final approval of the version to be published; and agree to be accountable for all aspects of the work.

\section{Funding}

This research was funded by the Ministry of Education and Culture, Republic of Indonesia.

\section{Disclosure}

The authors declare no conflicts of interest in this work.

\section{References}

1. Supadmi W, Suwantika AA, Perwitasari DA, Abdulah R. Economic evaluations of dengue vaccination in the Southeast Asia Region: evidence from a systematic Review. Value Health Reg Issues. 2019;18:132-144. doi:10.1016/j.vhri.2019.02.004.

2. Ministry of Health, Republic of Indonesia. Decree of the Directorate General of Disease Control and Environmental Health on the Action Plan for the Disease Control and Environmental Health Program in 2015-2019. Jakarta: Ministry of Health, Republic of Indonesia; 2015.

3. Ministry of Health, Republic of Indonesia. Indonesia Health Profile of 2016. Jakarta: Ministry of Health, Republic of Indonesia; 2016. 
4. Statistics of Indonesia. The Density of Bandung in 2008-2014. Available from: https://bandungkota.bps.go.id/linkTableDinamis/ view/id/10. Accessed November 10, 2020.

5. Ministry of Health, Republic of Indonesia. Regulation of the Minister of Health, Republic of Indonesia, Number 42 of 2013 on the Implementation of Immunization. Jakarta: Ministry of Health, Republic of Indonesia; 2013.

6. Indonesian Food and Drug Authority. Indonesian FDA has approved the distribution license of dengue vaccine in Indonesia. Available from: http://www.pom.go.id/new/index.php/view/berita/ 12076/Badan-POM-Menyetujui-Izin-Edar-Vaksin-Dengue-diIndonesia.html. Accessed November 10, 2020.

7. Lee BY, Connor DL, Kitchen SB, et al. Economic value of dengue vaccine in Thailand. Am J Trop Med Hyg. 2011;84(5):764-772. doi:10.4269/ajtmh.2011.10-0624.

8. Ali M. E-learning in the Indonesian education system. Asia Pacific Cybereducation J. 2005;1(2):15-24.

9. Aldrich C. Simulations and the Future of Learning: An Innovative (And Perhaps Revolutionary) Approach to e-Learning. San Francisco: Pfeiffer; 2005.

10. Sangra A, Vlachopoulos D, Cabrera N. Building an inclusive definition of e-Learning: an approach to the conceptual framework. Available from: https://files.eric.ed.gov/fulltext/EJ983277.pdf. Accessed November 10, 2020.

11. Garrison DR, Anderson T. E-Learning in the 21st Century. A Framework for Research and Practice. London: RoutledgeFalmer; 2003.

12. Jereb E, Šmitek B. Applying multimedia instruction in e-learning. Innov Educ Teach Int. 2006;43(1):15-27. doi:10.1080/ 14703290500467335.

13. Paragina F, Paragina S, Jipa A, Savu T, Dumitrescu A. The benefits of using MOODLE in teacher training in Romania. Procedia Soc Behav Sci. 2011;15:1135-1139. doi:10.1016/j. sbspro.2011.03.252.

14. Shim E. Cost-Effectiveness of dengue vaccination in the Philippines. Am J Trop Med Hyg. 2016;1-26.
15. Suwantika AA, Zakiyah N, Kusuma ASW, Abdulah R, Postma MJ. Impact of switch options on the economics of Pneumococcal Conjugate Vaccine (PCV) introduction in Indonesia. Vaccines (Basel). 2020;8(2):233. doi:10.3390/vaccines8020233.

16. Suwantika AA, Zakiyah N, Lestari K, Postma MJ. Accelerating the introduction of rotavirus immunization in Indonesia. Expert Rev Vaccines. 2014;13(4):463-472. doi:10.1586/14760584.2014.891940.

17. Suwantika AA, Postma MJ. Effect of breastfeeding promotion interventions on cost-effectiveness of rotavirus immunization in Indonesia. BMC Public Health. 2013;13(1):1106. doi:10.1186/1471-2458-13-1106.

18. Suwantika AA, Beutels P, Postma MJ. Cost-effectiveness of hepatitis A vaccination in Indonesia. Hum Vaccin Immunother. 2014;10 (8):2342-2349. doi:10.4161/hv.29353.

19. Suwantika AA, Boersma C, Postma MJ. The potential impact of COVID-19 pandemic on the immunization performance in Indonesia. Expert Rev Vaccines. 2020;19(8):687-690. doi:10.1080/ 14760584.2020.1800461.

20. Shepard DS, Suaya JA, Halstead SB, et al. Cost-effectiveness of a pediatric dengue vaccine. Vaccine. 2004;22(9-10):1275-1280. doi:10.1016/j.vaccine.2003.09.019.

21. Suwantika AA, Kautsar AP, Supadmi W, et al. Cost-effectiveness of dengue vaccination in Indonesia: considering integrated programs with wolbachia-infected mosquitos and health education. Int J Environ Res Public Health. 2020;17(12):4217. doi:10.3390/ijerph17124217.

22. Harapan H, Anwar S, Bustaman A, et al. Community willingness to participate in a dengue Study in Aceh Province, Indonesia. PLoS One. 2016;11(7):e0159139. doi:10.1371/journal.pone.0159139.

23. Allen MW. Guide to e-Learning: Building Interactive Fun and Effective Learning Program for Any Company. Hoboken, NJ: John Wiley and Sons, Inc.; 2003.

24. Li FW, Lau RW, Dharmendran P A three-tier profiling framework for adaptive e-learning. Proceedings of the 8th International Conference on Advances in Web Based Learning, Aachen. 2009; 158.

25. Clark RC, Mayer RE. e-Learning and the Science of Instruction. Hoboken, NJ: John Wiley and Sons, Inc.; 2003.
Patient Preference and Adherence

\section{Publish your work in this journal}

Patient Preference and Adherence is an international, peer-reviewed, open access journal that focusing on the growing importance of patient preference and adherence throughout the therapeutic continuum. Patient satisfaction, acceptability, quality of life, compliance, persistence and their role in developing new therapeutic modalities and compounds to optimize clinical outcomes for existing disease states are major areas of interest for the journal. This journal has been accepted for indexing on PubMed Central. The manuscript management system is completely online and includes a very quick and fair peer-review system, which is all easy to use. Visit http:// www.dovepress.com/testimonials.php to read real quotes from published authors. 